\title{
Lipase-catalysed production and chemical composition of diacylglycerols from soybean oil deodoriser distillate
}

\begin{abstract}
Diacylglycerols (DAG) were enzymatically produced by lipase-catalysed esterification of glycerol with fatty acids from soybean oil deodoriser distillate (SODD). Effects of reaction parameters such as reaction time, temperature, enzyme type, enzyme load, substrate molar ratio and water content, as well as the effect of molecular sieves as water adsorbent were studied. Lipozyme RM IM was determined to be the most effective among the lipases screened. The following conditions yielded 69.9\% DAG (all percentages are wt/wt): $4 \mathrm{~h}$ reaction time, $65{ }^{\circ} \mathrm{C}$ reaction temperature, $10 \%$ Lipozyme RM IM, 2.5:1 fatty acid to glycerol molar ratio, and $30 \%$ molecular sieves. DAG synthesis of $11.9 \%$ was still observed at $10 \%$ water content. After purification, the product oil contained $86.3 \%$ DAG. This oil consisted predominantly of 1,3-diolein (19.1\%), 1-oleoyl-3-linoleoyl-glycerol (18.2\%) and 1-oleoyl-2linoleoyl-glycerol (16.6\%). The fatty acid profile of the oil was similar to that of refined, bleached and deodorised (RBD) soybean oil. The \% ratio of 1,3- to 1,2-positional isomers of DAG was at 56:44.
\end{abstract}

Keyword: Deodoriser distillate, diacylglycerol, esterification, lipase, Lipozyme RM IM 